\title{
A Fraternidade como Garantia Constitucional aos Direitos da União Homoafetiva
}

\author{
La Fraternidad como Garantía Constitucional a los Derechos de la Unión \\ Homoafetiva.
}

\section{The Fraternity as a Constitutional Guarantee to the Rights of Homoafetive Union.}

\author{
Jéssica de F. Aurélio 1 \\ Deisemara T. Langoski ${ }^{2}$
}

\begin{abstract}
Resumo
Gênero e sexualidade sempre foram temas de importante discussão na área sóciojurídico. Nas últimas décadas, para a união homoafetiva foram garantidos vários direitos de família, tais como a divisão dos bens adquiridos e o sobrenome do parceiro por decisões judiciais, porém, ainda existem questões que tem divergências e preconceitos. No Brasil, recentemente, um grande passo foi dado nesse quesito, em 5 de maio de 2011, o Supremo Tribunal Federal, estendeu às uniões homoafetivas os mesmos direitos e deveres da união estável entre um homem e uma mulher. Por essa razão, o presente trabalho tem como objetivo analisar o princípio da fraternidade como defensor dos direitos da união homoafetiva. A metodologia utilizada foi o método de abordagem dedutivo e a pesquisa bibliográfica. Foram analisadas publicações, artigos e o voto do Ministro relator Carlos Ayres Britto na ADPF 132 que reconhece a proibição do preconceito como um capitulo do constitucionalismo fundamentado no princípio da fraternidade. A análise consiste em avaliar a teoria da fraternidade sob os fundamentos da Constituição Federal Brasileira a fim de obter soluções concretas e encontrar políticas públicas para o combate ao preconceito e assegurar direitos para a união homoafetiva. Este estudo trouxe o ensinamento para outras demandas por direitos fundamentais e mostrou que o Estado brasileiro teve conquistas nos aspectos jurídicos da questão de gênero e sexualidade, que trarão grandes benefícios jurídicos e sociais.
\end{abstract}

Palavras-Chave: Princípio da Fraternidade; União Homoafetiva; Direito à igualdade; Cidadania; Humanidade.

\section{Resumen}

Género y sexualidad siempre fueron temas de importante discusión en el área sociojurídico. En las últimas décadas, para la unión homoafectiva se han garantizado varios derechos de familia, tales como la división de los bienes adquiridos y el apellido del socio por decisiones judiciales, sin embargo, todavía existen cuestiones que tienen divergencias y prejuicios. En Brasil, recientemente, un gran paso fue dado en ese aspecto, el 5 de mayo de 2011, el Supremo Tribunal Federal, extendió a las uniones homoafetivas los mismos derechos y deberes de la unión estable entre un hombre y una mujer. Por esta razón, el presente trabajo tiene como objetivo analizar el principio de la fraternidad como defensor de los derechos de la unión homoafectiva. La metodología utilizada fue el método de abordaje deductivo y la investigación bibliográfica. Se analizaron publicaciones, artículos y el voto del Ministro ponente Carlos Ayres Britto en la ADPF 132 que reconoce la prohibición del prejuicio como un capitulo del constitucionalismo fundamentado en el principio de la fraternidad. El análisis consiste en evaluar la teoría de la fraternidad bajo los fundamentos de la Constitución Federal Brasileña a fin de obtener soluciones concretas y encontrar políticas públicas para el combate al prejuicio y asegurar derechos para la unión homoafectiva. Este estudio trajo la enseñanza a otras demandas por derechos fundamentales y mostró que el Estado brasileño tuvo conquistas en los aspectos jurídicos de la cuestión de género y sexualidad, que traerá grandes beneficios jurídicos y sociales.

${ }^{1}$ Graduanda do Curso de Direito. Universidade Federal do Pampa (UNIPAMPA - Campus Santana do Livramento). Integrante do Grupo de Pesquisa Direito, Cidadania e Fraternidade E-mail: jecaurelio@hotmail.com.

${ }^{2}$ Doutora em Direito pela UFSC. Professora do Curso de Direito da UNIPAMPA - Campus Santana do Livramento. E-mail: deiselangoski@gmail.com. 
Palabras claves: Principio de la Fraternidad; Unión Homoafetiva; Derecho a la igualdad; la ciudadanía; La humanidad.

\begin{abstract}
Gender and sexuality have always been topics of important discussion in the social-legal area. In the last decades, several family rights have been guaranteed for the homoafetive union, such as the division of acquired goods and the surname of the partner by judicial decisions, but there are still issues that have divergences and prejudices. In Brazil recently, a major step was taken in this regard, on May 5, 2011, the Federal Supreme Court extended homosexual unions the same rights and duties of a stable union between a man and a woman. For this reason, the present work aims to analyze the principle of fraternity as a defender of the rights of homoafetive union. The methodology used was the method of deductive approach and bibliographical research. Publications, articles and the vote of the Minister Rapporteur Carlos Ayres Britto in ADPF 132 were analyzed, recognizing the prohibition of prejudice as a chapter of constitutionalism based on the principle of fraternity. The analysis consists of evaluating the theory of fraternity under the foundations of the Brazilian Federal Constitution in order to obtain concrete solutions and find public policies to combat prejudice and ensure rights for homoaffective union. This study brought the teaching to other demands for fundamental rights and showed that the Brazilian State has achieved achievements in the legal aspects of the issue of gender and sexuality, which will bring great juridical and social benefits.
\end{abstract}

Keywords: About five keywords of phrases in alphabetical order, separated by semicolon.

\title{
1. Introdução
}

Os estudos sobre gênero e sexualidade estão sempre em constante discussão e debates na academia, fator que contribui para as dinâmicas da vida sociocultural e as demandas no âmbito do direito. Desta maneira, estes setores precisam de novos recursos teóricos e pesquisas a respeito da união homoafetiva para o enfrentamento dos mais variados desdobramentos jurídicos, a fim de alcançar a pacificação com justiça social.

A motivação deste estudo vem da importância de assegurar os direitos da união homoafetiva em todos os níveis jurídicos e sociais, em especial, ao apresentar o princípio da fraternidade como valor princípio para a garantia da segurança constitucional a liberdade da sociedade. Mesmo com percalços pelo caminho, já dizia Nelson Mandela, “Liberdade parcial não é liberdade”.

Deste modo, o tema de pesquisa refere-se ao estudo do princípio da fraternidade para assegurar os direitos sóciojuridicos no âmbito do gênero e sexualidade. A delimitação do tema consiste nos direitos da união homoafetiva na legislação brasileira. A avaliação dos questionamentos é alcançada pelo levantamento bibliográfico.

Este artigo procura responder o seguinte problema de pesquisa, como o princípio da fraternidade assegura os direitos constitucionais da união homoafetiva? E, como objetivo busca-se analisar a fraternidade como valor princípio para a garantia dos direitos da união homoafetiva. Além disso, este estudo apresenta os seguintes objetivos específicos: 1) Aplicar 
as normativas da Constituição Brasileira; 2) Contribuir para a valorização dos direitos da união homoafetiva no Brasil; 3) Avaliar como o direito fraterno pode contribuir para a questão de gênero e sexualidade.

Ao evidenciar a importância do estudo dos direitos da união homoafetiva, procura-se mostrar que a fraternidade pode solucionar divergências socioculturais, a exemplo das questões homoafetivas, pois é um tema que encontra-se em constante debate na área do direito. Também salienta-se que existem poucas pesquisas acadêmicas sobre o assunto. A pesquisa é delineada no âmbito de se obter suposições acerca dos direitos ideais para a obtenção garantias constitucionais.

A metodologia empregada aborda o método dedutivo com a técnica de pesquisa bibliográfica. Foram analisadas publicações, periódicos e o voto do Ministro relator Carlos Ayres Britto na ADPF 132 que reconhece a proibição do preconceito como um capítulo do constitucionalismo fundamentado no princípio da fraternidade. Dividiu-se o artigo em duas partes: inicialmente analisou-se o Princípio da Fraternidade e, em seguida a questão do gênero e da sexualidade, a fim de elucidar o problema de pesquisa.

\section{Princípio da Fraternidade}

Para buscar um melhor entendimento de como o princípio da fraternidade pode garantir os direitos da união homoafetiva, é importante analisar o contexto histórico e algumas definições desse princípio. De acordo com LANGOSKI (2017), a Revolução Francesa foi um marco na história mundial, pois modificou ideias político-ideológicas por todo mundo, e foi nessa época, onde o conceito de fraternidade começou a ganhar mais importância na famosa divisa da revolução: liberdade, igualdade e fraternidade. E assim, ganhou distintos significados, procurava revelar a ocasião vivida pelos franceses revolucionários. Porém, a base fundamental da fraternidade está no amor do homem pelo homem, no dever mútuo, no Direito e na Justiça. Ainda assim, ERNANDORENA (2012) diz que é de grande valia avaliar a fraternidade como categoria jurídico-constitucional, de modo que os valores expressos não fiquem apenas em nível de consciência moral.

Como já foi citado anteriormente, este princípio teve início na Revolução Francesa, porém, hoje os autores tem diferentes definições. Para LANGOSKI (2017), A fraternidade não é uma concepção fechada e única, tem uma ampla rede de significados e de avaliações que pode conter múltiplos sentidos. 
Vindo dos três pilares da Revolução, NUNES e PILATI (2014) resumem que é essencial e indispensável o princípio da fraternidade para a plena realização da liberdade e da igualdade. Também é importante considerar a fraternidade como princípio motriz de práticas democráticas de caráter coletivo-participativo. Movimentos sociais sejam defensores, representantes de parcelas expressivas da sociedade, contrapondo-se a todas as formas de preconceito, por meio de uma atitude fraterna baseada na comunhão de interesses e experiências. Os autores ainda dizem que a fraternidade permite a formulação de ideias do povo, gerando a identidade de setores sociais, sendo um primeiro passo para a conquista de novos direitos e para a estabilização de interesses coletivos.

NUNES e PILATI (2014) apud FLORES (2009) assinalam cinco deveres básicos para que uma nova teoria dos direitos humanos, desenvolvida por meio de uma prática coletiva e fraterna seja possível, são eles: Reconhecimento, Respeito, Reciprocidade, Responsabilidade e Redistribuição.

Segundo MARTINI e RUBINO (2018) a perspectiva do direito fraterno deve ser conjunta e compartilhada, afim de evitar qualquer tipo de imposição. A fraternidade, no entanto, pode ser atraídos em leito cultural e política das grandes narrativas como possíveis, como a da esperança Princípio (Ernst Bloch), ou a Responsabilidade Princípio (Hans Jonas), a condição de unicidade (Peter Kemp). A ética comum é diretamente ligada a fraternidade, elas se completam. Quanto mais temos bens comuns disponíveis, mais aumenta a responsabilidade do ser humano, e princípios como fraternidade, esperança e solidariedade devem se destacar.

A teoria da fraternidade sob os fundamentos da Constituição Federal Brasileira é importante para alcançar respostas eficientes e localizar políticas públicas que enfrentem o preconceito e aprovem direitos para a união homoafetiva. ERNANDORENA (2012, p. 7-8) diz que a Constituição Brasileira não relaciona a fraternidade entre os princípios fundamentais inscritos no artigo $1^{\circ}$, porém isso não quer dizer que ela não alcance o status de princípio constitucional.

Ainda segundo o autor, o preâmbulo da Constituição de 1988 não deixa margem de dúvida ao referir expressamente o propósito de instituir os "valores supremos de uma sociedade fraterna”, pois o texto confirma isso:

Nós, representantes do povo brasileiro, reunidos em Assembléia Nacional Constituinte para instituir um Estado Democrático, destinado a assegurar o exercício dos direitos sociais e individuais, a liberdade, a segurança, o bem-estar, o desenvolvimento, a igualdade e a justiça como valores supremos de uma sociedade fraterna, pluralista e sem preconceitos, fundada na harmonia social e comprometida, na ordem interna e internacional, com a solução pacífica das controvérsias, 
ERNANDORENA (2012) também mostra que dois incisos da Constituição podem elucidar esse conceito. Primeiro o princípio da fraternidade pode ser inferido do inciso III, do artigo $1^{\circ}$, da Lei Maior, ao constituir como um dos fundamentos da República a “dignidade da pessoa humana”, como pode ser visto abaixo.

Art. $1^{\circ}$ A República Federativa do Brasil, formada pela união indissolúvel dos Estados e Municípios e do Distrito Federal, constitui-se em Estado Democrático de Direito e tem como fundamentos:

$[\ldots]$

III - a dignidade da pessoa humana;

[...] (Brasil, 1988).

Após isso, é visto entre os objetivos fundamentais, encontra-se, na expressão “sociedade livre, justa e solidária” (art. $3^{\circ}$, inciso I), um canal de comunicação explícito e direto com a ideia de fraternidade.

\section{Gênero e Sexualidade}

A união homoafetiva é um assunto de importante discussão nos dias atuais, pois cada vez mais, todos países estão adaptando suas legislações para incluí-lo nos ordenamentos. Dentro desse contexto, NETO (2014, p. 12) diz que notícias e informações ligadas a sexualidade aparecem seguidamente nos meios de comunicação, desde leis, ocupação no mercado de trabalho, protestos em público, e principalmente, grandes disputas parlamentares para aprovar leis que mudem padrões, como o casamento, por exemplo. Tudo isso faz parte de um mundo que segue escondido, uma realidade que o direito precisa agir com sua vocação normativa. Ainda conforme o autor, o direito se relaciona com a sexualidade através das normas que regem os sujeitos e suas relações da vida humana, em muitas das quais a sexualidade é importante na construção e vivência dessas relações.

O panorama político brasileiro atual põe em risco vários avanços sociais no âmbito dos direitos das mulheres e da população de lésbicas, gays, bissexuais, travestis e transexuais/transgêneros (LGBT), obtidos nas últimas décadas, aprofundando sobremaneira as desigualdades de gênero. A discriminação e as desigualdades sociais não conseguirão ser 
reduzidas, segundo BRANDÃO e LOPES (2018) o debate sobre gênero e sexualidade pode diminuir o machismo e a aversão às mulheres, pode elucidar a igualdade de gênero e a diversidade sexual através do estudo das diferenças socioculturais. Os autores ainda citam que essa problemática precisa ser discutida, pois contribui para a afirmação dos direitos humanos no Brasil.

Para abordar sobre gênero e sexualidade, não tem como não falar da disputa política que os direitos humanos vem enfrentando, nesse contexto, de acordo com VASCONCELOS e FELIX (2016) temos um exemplo dessa disputa, a retirada das questões de gênero e sexualidade do documento final do Plano Nacional de Educação 2014-2024 depois da força das bancadas mais conservadoras do Congresso Nacional.

Conforme DÍAZ-BENÍTEZ e GONÇALES (2018), gênero e sexualidade no Brasil não são terrenos neutros, as relações de poder os envolvem. Os autores utilizam a metáfora do boxe para fazer um resumo sobre os diversos golpes que têm acontecido nas últimas duas décadas em relação a esse tema. Os autores citam um histórico dos direitos de gênero e sexualidade no Brasil, que começa nos anos 90, pois a epidemia de HIV/AIDS representou um marco para o fortalecimento de ações em torno da população LGBT. Todavia, os anos 2000 foram de grande importância para esses direitos, no âmbito Executivo Federal foi implementado o programa Brasil sem Homofobia em 2004 e o projeto de Lei da Câmara 122/2006 que criminaliza a homofobia. Mais recentemente, os autores mencionam o reconhecimento dos direitos relativos a uniões estáveis ocorrido em 2011 no Supremo Tribunal Federal, uma das maiores conquistas no âmbito Judiciário, que será melhor explicado a seguir.

Dentro dessa análise é importante saber que foi no julgamento da ADI n. 4.277, em maio de 2011, que o Supremo Tribunal Federal (STF) reconheceu juridicamente as uniões estáveis homoafetivas “com as mesmas regras e consequências da união estável heteroafetiva”. De acordo com MAUÉS (2015) essa determinação aproximou críticas da sociedade jurídica e resistências na própria esfera judicial, pois existem duas linhas de argumentos nessas apreciações. A primeira considera que a Constituição proíbe o reconhecimento de uniões entre pessoas do mesmo sexo, enquanto a segunda afirma que, embora a Constituição não proíba o reconhecimento da união homoafetiva, o judiciário não tem competência para tomar essa decisão. $\mathrm{O}$ autor enfrenta ambas as críticas, aproveitando como referência a teoria do direito como integridade de R. Dworkin.

CAULFIELD (2017) diz que defensores dos direitos LGBT prepararam o terreno para a legalização do casamento homoafetivo no Brasil por meio de diversas influências culturais e 
do discurso dos direitos humanos. A autora cita um importante fato ocorrido em 2013, quando o Conselho Nacional de Justiça (CNJ) determinou que os cartórios em todo o país passassem a registrar também os casamentos entre pessoas do mesmo sexo, acabando com a resistência por parte de alguns oficiais e juízes

DÍAZ-BENÍTEZ e GONÇALES (2018) também citam a Lei João W. Nery (Identidade de Gênero) que tem como embasamento a lei argentina de identidade de gênero e no artigo $2^{\circ}$ do projeto de lei, aparece a seguinte definição: "Entende-se por identidade de gênero a vivência interna e individual do gênero tal como cada pessoa o sente, a qual pode corresponder ou não com o sexo atribuído após o nascimento, incluindo a vivência pessoal do corpo".

Todos estes artifícios citados serviram como desenvolvimento dos direitos no âmbito de gênero e sexualidade, entretanto, a luta pela melhoria desses principais pontos sóciojuridicos deve ser permanente na academia, pelos operadores jurídicos e legisladores a fim de ampliar e assegurar os direitos da união homoafetiva.

\section{Conclusões}

Este artigo buscou ratificar a importância do estudo do princípio da fraternidade aliado ao gênero e sexualidade, é de grande valia novos estudos que busquem políticas públicas inovadoras para garantir os direitos da união homoafetiva. Evidencia-se que contemporaneamente que os direitos estão evoluindo, porém, é necessário não estagnar esse desenvolvimento teórico, jurídico e legislativo e procurar a melhoria desses direitos. Destacase também a dificuldade de encontrar produção cientifica a respeito do tema da união homoafetiva, gênero e sexualidade.

Este trabalho originou o aprendizado de direitos fundamentais e mostrou que a sociedade brasileira já obteve conquistas nos aspectos jurídicos da questão de gênero e sexualidade e também do assunto da fraternidade como princípio jurídico constitucional, mas que deve continuar em busca de mais progresso. O objetivo pretendido por este estudo foi atendido, pois as pesquisas comprovaram que o princípio da fraternidade pode sim garantir direitos da união homoafetiva. O trabalho contribui par motivar os estudos no tema e para que se busquem mais artifícios jurídicos que possam defender esta importante segmento da sociedade, com direitos justos e igualitários. Para trabalhos futuros, seria ideal analisar com maior dedicação e esmiuçar a legislação brasileira e os direitos humanos a fim de avalizar os direitos da união homoafetiva. 


\section{Referências}

BRANDÃO, E. R.; LOPES, R. F., “Não é competência do professor ser sexólogo”: o debate público sobre gênero e sexualidade no Plano Nacional de Educação. Civitas Revista de Ciências Sociais, [S.l.], v. 18, n. 1, p. 100-123, 2018. ISSN 1984-7289. Disponível em: <http://revistaseletronicas.pucrs.br/ojs/index.php/civitas/article/view/28265 >. Acesso em: 28 dez. 2018. Doi: http://dx.doi.org/10.15448/1984-7289.2018.1.28265.

BRITTO, Ayres, ADI n. 4.277, Disponível em: $<$ http://redir.stf.jus.br/paginadorpub/paginador.jsp?docTP=AC\&docID=628635> $\quad$ Acesso em: 20 dez. 2018.

CAULFIELD, S., A dignidade humana, o direito de família e o casamento homoafetivo no Brasil, 1988-2013. Acervo, Rio de Janeiro, V. 30, N. 1, P. 179-194. 2017. Disponível em: <http://oaji.net/articles/2017/3932-1500402199.pdf> Acesso em: 27 dez. 2018.

DÍAZ-BENÍTEZ, M. E.; GONÇALES, N. F., Por dentro do ringue: gênero e sexualidade no embate da inclusão por direitos. Revista Ñanduty, ISSN 2317-8590, 2018.

ERNANDORENA, P. R., Resolução de conflitos ambientais no Brasil: do patriarcal ao fraternal. Estud. soc [online]. vol.20, n.40, pp.11-30. ISSN 0188-4557. 2012.

FLORES, H. J., A (Re)Invenção dos Direitos Humanos. Florianópolis: Boiteux, 2009a.

LANGOSKI, D. T., Os efeitos do reconhecimento da diversidade sexual como um direito humano pelo sistema interamericano de proteção. Tese de Doutorado, Universidade Federal de Santa Catarina, Centro de Ciências Jurídicas. Programa de Pós-Graduação em Direito, 2017.

MARTINI, S. R.; RUBINO, F., Il diritto fraterno e il paradosso dei beni comuni dell'umanità. Revista Direito e Justiça: Reflexões Sociojurídicas, Santo Ângelo, v. 18, n. 31, p. 125-144, ISSN: 2178-2466, 2018. Doi: http://dx.doi.org/10.31512/rdj.v18i31.2684.

MAUÉS, A. M.. Capítulos de uma história: a decisão do STF sobre união homoafetiva à luz do direito como integridade. Seqüência: Estudos Jurídicos e Políticos, Florianópolis, v. 36, n. 70, p. 135-162, ISSN 2177-7055, jun. 2015. Disponível em: $<$ https://periodicos.ufsc.br/index.php/sequencia/article/view/2177-7055.2015v36n70p135>.

Acesso em: 04 jan. 2019. doi: https://doi.org/10.5007/2177-7055.2015v36n70p135.

NETO, C. E., Os efeitos do reconhecimento da diversidade sexual como um direito humano pelo sistema interamericano de proteção. 184f. Dissertação (Mestrado em Direito) - Centro de Ciências Sociais Aplicadas, Universidade Federal do Rio Grande do Norte, Natal, 2014.

NUNES, F. P; PILATI, J. I., A fraternidade como princípio ético necessário para uma nova práxis coletiva e emancipatória em direitos humanos. Revista Eletrônica do Curso de Direito da UFSM, Santa Maria, RS, v. 9, n. 2, p. 381-401, ISSN 1981-3694. dez. 2014. Disponível em: <https://periodicos.ufsm.br/revistadireito/article/view/15754>. Acesso em: 04 jan. 2019. doi: http://dx.doi.org/10.5902/1981369415754. 
VASCONCELOS, M. F.; FELIX, J., Gênero, sexualidade e direitos humanos na educação escolar: entre igualdades e diversidades, a diferença. Revista Reflexão e Ação, Santa Cruz do Sul, v. 24, n. 1, p. 255-272, 2016. ISSN on-line: 1982-9949. Doi: 10.17058/rea.v24i1.6787 